\title{
Research on Behavior of Regulators and Enterprises about Carbon Emissions Based on Game Theory
}

\author{
Honglei Tang ${ }^{1, *}$ and Guofang Song ${ }^{2}$ \\ ${ }^{I}$ Huzhou Teachers College, Huzhou 310000, P.R. China; School of management, Shanghai University, Shanghai \\ 200000, PR China \\ ${ }^{2}$ School of management, Shanghai University, Shanghai 200000, P.R. China
}

\begin{abstract}
Because of many principals involved in the process of carbon reduction, government regulation often presents some problems, which are harmful to the environment. In order to minimize the harm to the environment, the government regulators should study enterprises' behavioral characteristics and the corresponding regulatory policy. This paper built the enterprises behavioral choice model of signal transmission game, analyzed four kinds of refining Bias equilibrium which include the confused equilibrium, separation equilibrium and the semi-separating equilibrium, and solved semi separating equilibrium. The study found that the appropriate regulatory measures of government departments would increase the cost of enterprises' false declaration, and standardize market order.
\end{abstract}

Keywords: Behavior, carbon emissions, game theory.

\section{INTRODUCTION}

Carbon dioxide emissions associated with climatic change caused great damage to the world's economy; the development of low-carbon economy has become a matter of concern to the international community. The Intergovernmental Panel on climate change (IPCC) published its fourth assessment report on climatic change in the past 100 years, the global average surface air temperature has risen to $0.3-0.6{ }^{\circ} \mathrm{C}$ caused by gases, such as carbon dioxide greenhouse gases. The reason of climatic change in the past 50 years is mainly anthropogenic emissions of carbon dioxide, methane, nitrous oxide and other greenhouse gases; and it predicted the global average temperatures would raise to 1.8$4{ }^{\circ} \mathrm{C}$. The environment has faced intensive pressure and it is difficult to reduce the carbon emissions, and due to the asymmetric information in the carbon emissions reduction process, leading to misallocation of resources, efficiency is not high.

\section{LITERATURE REVIEW AND QUESTIONS}

From the "Kyoto Protocol" and "Bali Action Plan" and the world climate conference in Copenhagen and Cancun, low-carbon concept received increasing attention of governments and all sectors of society, the literature about lowcarbon economy is also growing.

Foreign literature study carbon emissions reduction issues from a wider perspective. For example, Roberto and Francesco Bosello Roson [1] analyzed the international car

*Address correspondence to this author at the Huzhou Teachers College, China; Fax:+86 572 2321105; Tel: +86 13738231232;

E-mails: hlttj@126.com, hzttj@hutc.zj.cn bon trade issues, and the different trade regimes can lead to very different distributional effects. Jan Christoph Steckel [2], a researcher, who studied about one of the recent hot topics: carbon emission reduction measures should be based on the production or consumption. They quantitatively analyzed the differences in estimating carbon emissions in two ways, as well as the differential impact on States incentives to reduce carbon emissions. Research has shown that under the global trade system of limits and given an initial distribution, based on the production and consumption to measure carbon emissions will not affect the final result of the allocation and efficiency. Corbett Grainger [3] has used inputoutput models to analyze survey data of the consumers of the United States. The study has shown that for energy-intensive commodities, consumption patterns are the most important factors affecting the price of carbon, carbon prices based on family is far less accurate than the price based on capital. Salvador Enrique Puliafito, et al. [4] used mathematics model for the study on relationship between population, GDP, energy consumption and carbon emissions. Michael Dalton, et al. [5] used the $\mathrm{PET}^{1}$ model to validate this conclusion. With the transformation of the world's population, the population is gradually being highlighted, before and after 2020 in the developed countries entered the aging society, population ageing factors that can reduce carbon emissions, the effects of this phenomenon was same as the effects of technological changed. Ugur Soytas, et al. [6] used the $\mathrm{VAR}^{2}$ model including GDP, energy consumption, carbon dioxide emissions, labour and gross fixed capital, and other variables to research on United States energy consumptions, causal relationships between GDP and carbon emissions.

\footnotetext{
${ }^{1}$ PET: Petri model

${ }^{2}$ VAR: Vector Auto Regression
} 
The national scholars are also very concerned about the topic of carbon emissions. Research methods and research perspectives are similar to foreign scholars. For example, $\mathrm{Xu}$ Yingzhi and Zou Fang [7] studied the indirect effect and partial transfer mechanisms of carbon emissions in the production and consumption activities of the 27 industrial sectors in China from input-output perspective, through the construction of input-output model from the industry level effect. The study has shown that industries in carbon emissions reduction responsibilities presented different characteristics. Wang Mingxi, Wang Mingrong, Wang shouyang [8], based on our 2020 targets of carbon emissions reduction, researched firm strategy of carbon emissions reduction, and analyzed when enterprises independent investment in carbon emissions reduction policy deviated from the optimal investment strategy of carbon emissions reduction, the corrective measures and economic instruments should be taken. They also studied the measurement and control of emission reduction investment uncertainty, who proposed to make relevant policy recommendations, and noted that the issue deserves further study in the future. Li Xiaoping and $\mathrm{Lu}$ Xianxiang [9] have selected an international comparative perspective, using methods such as environmental inputoutput model and net exporter of the consumer price index, 20 industrial sectors in China and developed countries such as the $\mathrm{G} 7, \mathrm{OECD}^{3}$ trade data were used for an empirical test, and the result has proved that China did not adopt international trade "pollution industrial paradise." Other scholars also analyzed this question from various aspects, and the methods they used were diversified. For example, Ba Shusong and Wu Dayi [10] have used VAR model and analysis of impulse response function method for building the cost of carbon dioxide emission reduction calculation model to analyze the relationships among the energy consumption, carbon dioxide emissions and economic growth. The emissions reductions will cause the negative effects in the investment, output and employment of China economic. Presently, a better choice would be to implement fuel switching policies. Wang Zhongying and Wang Limao [11] researched on the relationship between China's economic growth and carbon emissions reduction through related analysis method. They have a significant correlation. As economic growth, the carbon emissions will increase. Many measures such as adjusting the industrial structure, improving energy efficiency and the transformation of economic growth mode can reduce the carbon emissions. Yu Rong and Zhu Xian [12] have built the indicators of the efficiency of economic growth in China through co-integration analysis and causality analysis. China's carbon emissions have exceeded the level of contribution to economic growth, and it is reducing year by year. So it is necessary to take measures progressively to control carbon emissions. These conclusions differ from the study abroad. As a developing country, it is a particular problem how to deal with the contradiction between economic growth target and carbon emissions.

The existing literature which is from different aspects to study carbon emissions in view of a low-carbon economy, provided a good basis for this article, but it can also be seen,

\footnotetext{
${ }^{3}$ OECD: Organization for Economic Co-operation and Development
}

many related subjects were not involved in analysis of carbon emissions into a unified framework in most of the literature, also failed to reveal the game mechanism among the relevant subjects. This paper has a try to analyze this question with game theory.

\section{SIGNALING GAME MODEL IN THE CARBON REDUCTION PROCESS}

\subsection{Basic Assumptions}

(1) Game participant are carbon-emissions-dependent enterprises and government regulators;

(2) Enterprises and regulators are "rational man", cooperation between the two sides aim is to maximize their own income or utility;

(3) Type of production enterprises is environmentalfriendly enterprises or environmental pollution, respectively, using $g$ for representing environment-friendly enterprises, and $b$ for environmental-pollution enterprises. Assuming its type of production is mainly decided by the cost of carbon dioxide emission reduction, and the cost of carbon emissions reduction for environmental-pollution enterprises is greater, that is $C_{a}^{b}>C_{a}^{g}$;

(4) Information asymmetry that exists between enterprises and regulators, regulators do not know the enterprise production technology, energy efficiency and carbon emission reduction, integrity and other private information. Enterprises know that regulators clearly have public information, considering enterprises production types of private information only;

(5) Regulators do not understand the business of production types, but through other means, such as enterprises production types, production equipment and prior releases of its type have a priori judgment. The probability of regulators judging the company as environmental-friendly enterprises is: $p(g)$, and the probability of environmental-pollution enterprises is: $p(b)$, and $p(g)+p(b)=1$;

(6) It is a process of dynamic games of incomplete information that regulators choose to supervise enterprises or not. Order of the game: the first phase of "nature" as a "virtual participant" to select enterprises production mode; the second phase, according to the choice of "nature", enterprises send regulators the best signal for themselves, namely decision reported to the regulator high carbon emissions, or low carbon emissions, respectively, used for $p_{h}$ and $p_{l}$; the third phase, according to the signals observed by the regulators, regulators using Bayesian principle to amend prior probabilities, are posterior probability of enterprises production mode, and regulators choosing to supervise or not according to the posterior probability. That is: $\operatorname{prob}(g \mid l)$, $\operatorname{prob}(g \mid h), \operatorname{prob}(b \mid l), \operatorname{prob}(b \mid h)$.

(7) No matter what type of business can bring to regulators certain social values, respectively, are recorded as: $\theta_{g}$ 


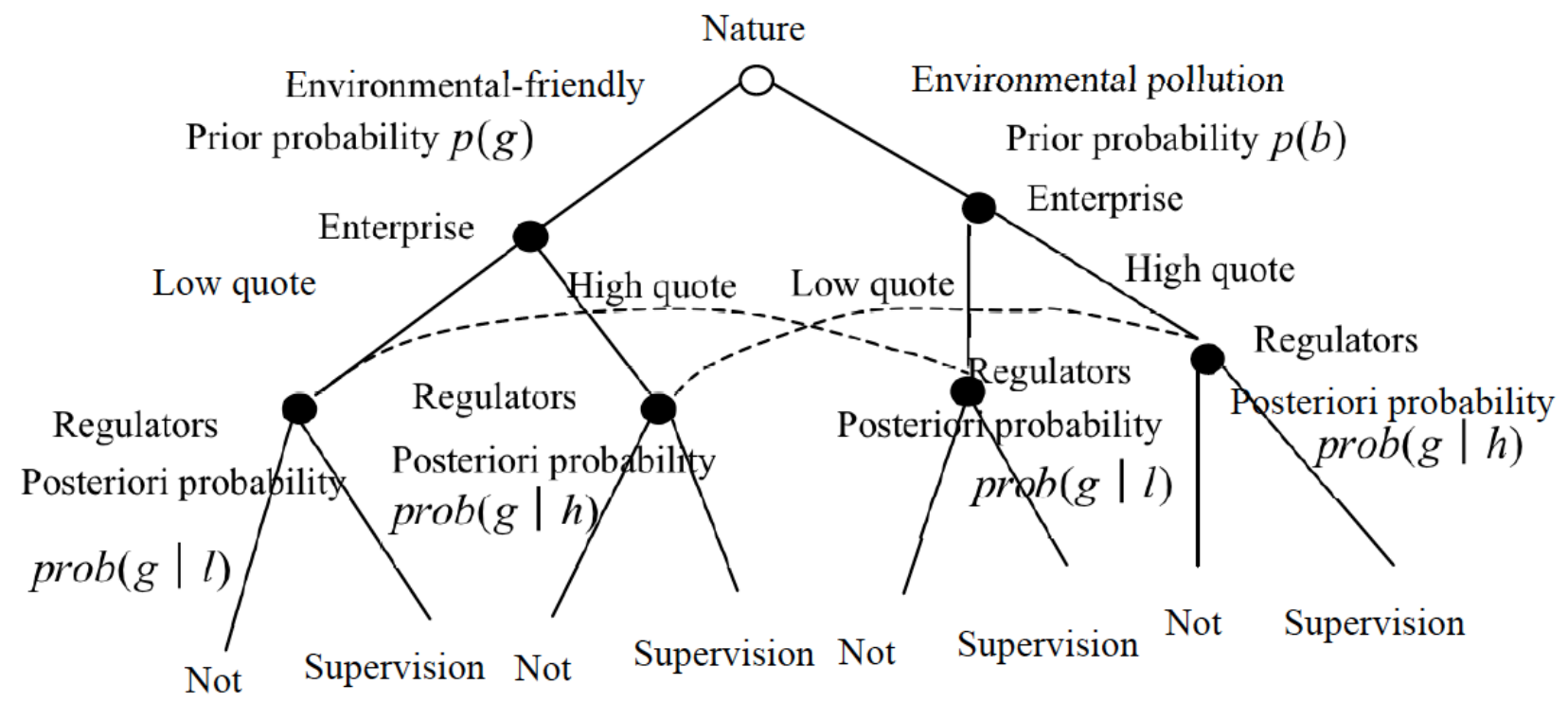

Fig. (1). The process of signal game.

and $\theta_{b}$. The value that environmental-friendly enterprises brought to regulators is better than environmental pollution enterprises, that is: $\theta_{g}>\theta_{b}>0$;

(8) Assuming that environmental governance costs and carbon emissions is the linear relationship, the governance factor is: $t$, the governance factor of environmental-friendly enterprises is: $t_{g}$, the governance factor of environmental pollution enterprises is: $t_{b}$; enterprises need to pay carbon taxes can be easy to record: $T_{g h}=t_{g} p_{h}, T_{g l}=t_{g} p_{l}$ and $T_{b h}=t_{b} p_{h}, T_{b l}=t_{b} p_{l}$.

(9) Assume that when regulators have made regulatory decisions, the regulatory cost is: $C_{m}$, and the probability of regulators are able to identify whether the carbon emissions exceeded the level. When found to be discharged yet false reports of emissions, enterprises not only need to pay a carbon tax, but needed to pay the fine. When the emissions by identifying emissions were false, enterprises not only needed to pay a carbon tax $\Delta T$, but also needed to pay a fine $F$;

(10) High carbon emission enterprises to avoid carbon taxes are considered to obtain extra profits, to pay certain cost in order to deceive regulators rational judgment.

Based on the above assumptions, if only under the conditions of the social value of government regulators, net income from their expected social value is:

$$
\begin{aligned}
& E(\theta)=\operatorname{prob}(g \mid l)\left(\theta_{g}-t_{g} p_{l}\right)+\operatorname{prob}(g \mid h)\left(\theta_{g}-t_{g} p_{h}\right)+ \\
& \operatorname{prob}(b \mid l)\left(\theta_{b}-t_{b} p_{l}\right)+\operatorname{prob}(b \mid h)\left(\theta_{b}-t_{b} p_{h}\right)
\end{aligned}
$$

When $E(\theta)>0$, government regulators choose to maintain the status quo, that is: not regulate enterprises; when $E(\theta)<0$, government regulators choose to regulate enterprises.

\subsection{Behavior Selection Model Based on Signaling Game}

"Signal" refers to the possession of information superiority for enterprises to adopt a course of action to send related signals to the regulators, for helping the government departments to avoid adverse selection risk, or compensate for the imperfections of the market mechanism. It is a way to show true information. Signal game of both process and net income is shown in Fig. (1).

Behavior selection model of enterprise based on signal game includes three refined Bayesian equilibriums: pooling equilibrium, separating equilibrium, and semi-separating equilibrium.

\subsubsection{Pooling Equilibrium}

When $p_{l}-C_{a}^{b}-\rho>p_{h}-C_{a}^{b}$, and $p(g)>\frac{p(b)\left(t_{b} p_{l}-\theta_{b}\right)}{\left(\theta_{g}-t_{g} p_{l}\right)}$,

it is pooling equilibrium. Strategies of enterprise and government regulators are: no matter environmental friendly enterprises or environmental pollution enterprises all send signals of high carbon emissions. The regulators will not choose to supervise enterprises when the carbon emissions do not meet the environmental threshold. Pooling equilibrium means that different types of production enterprises choose to send the same signal in carbon emissions. Therefore, the posterior probability of the government regulators on the enterprises production mode is:

$$
\begin{aligned}
& \quad \operatorname{prob}(g \mid h)=p(g), \quad \operatorname{prob}(g \mid l)=0, \quad \operatorname{prob}(b \mid h)=p(b), \\
& \operatorname{prob}(b \mid l)=0 .
\end{aligned}
$$

According to (1) the expected net social value from government regulators is: $E(\theta)_{\text {pooling equilibrium }}=p(g)\left(\theta_{g}-t_{g} p_{h}\right)+p(b)\left(\theta_{b}-t_{b} p_{h}\right)>0$.

As an environmental friendly enterprise can bring to public value must be much greater than environmental pollu- 
tion enterprise, especially in today's environment has become increasingly valued, that is: $\theta_{g}-t_{g} p_{h}>0>\theta_{b}-t_{b} p_{h}$. When $p(g)>\frac{p(b)\left(t_{b} p_{l}-\theta_{b}\right)}{\left(\theta_{g}-t_{g} p_{l}\right)}, E(\theta)_{\text {pooling equilibrium }}>0$, so in this case, regulators even if choose not to supervise, also would not bring the government's lack of credibility and environmental issues. From another side, when $\operatorname{prob}(g \mid h)=p(g)$ is large enough, regulators are under judgment a priori or a posteriori judgments, it can be considered that there are enough environmental friendly enterprises, then choosing supervisions will result in a waste of social resources. So choosing not to supervise is consistent with rational judgment.

\subsubsection{Separating Equilibrium}

When $p_{h}-C_{a}^{g}>p_{l}-C_{a}^{b}-\rho$, it is separating equilibrium. Strategies of production enterprises and regulators are: environmental friendly enterprise of high quote carbon emissions, and environmental pollution enterprise of low quote carbon emissions; Government regulators choose not to supervise. Therefore, the posterior probability of production mode judged by regulators is: $\operatorname{prob}(g \mid h)=1, \operatorname{prob}(g \mid l)=0$, $\operatorname{prob}(b \mid h)=0, \quad \operatorname{prob}(b \mid l)=1$.

According to (1) regulators' expected net social value is:

$$
E(\theta)_{\text {separating equilibrium }}=\theta_{g}-t_{g} p_{h}+\theta_{b}-t_{b} p_{l}>0 \text {. At this }
$$

point, the regulators choose not to supervise that will obtain greater proceeds than to supervise, and the reporting signals of carbon emissions accurately reflect the types of production enterprises in this process and meet the separating equilibrium strategies constituting the perfect Bayesian equilibrium, which is one of the most efficient market equilibriums.

\subsubsection{Semi-separating Equilibrium}

The semi-separating equilibrium refers to an environmental friendly enterprise of high quote carbon emissions, and an environmental pollution enterprise with random probability high or low quote carbon emissions. Assuming the probability of environmental pollution enterprises of high quote carbon emissions is $\phi$, and the probability of low carbon emissions is $1-\phi$, and $0<\phi<1$. According to Bayesian principle the posteriori probability of regulators is: $\operatorname{prob}(g \mid h)=\frac{\operatorname{prob}(h \mid g) p(g)}{\operatorname{prob}(h \mid g) p(g)+p(h \mid b) p(b)}=\frac{p(g)}{p(g)+\phi p(b)}$ $>\frac{p(g)}{p(g)+p(b)}=p(g)$, $\operatorname{prob}(b \mid h)=\frac{\operatorname{prob}(h \mid b) p(b)}{\operatorname{prob}(h \mid b) p(b)+\operatorname{prob}(h \mid g) p(g)}=\frac{\phi p(b)}{\phi p(b)+p(g)}$ $<\frac{p(b)}{p(b)+p(g)}=p(b)$, $\operatorname{prob}(g \mid l)=0 ; \operatorname{prob}(b \mid l)=1-\phi_{\circ}$

In the semi-separating equilibrium, if the production enterprise of low quote carbon emissions, then it must be environmental pollution enterprise, because environmental friendly enterprise of low quote carbon emissions probability is zero; If the production enterprise of high quote carbon emissions, its type of production cannot be judged, but compared to prior probabilities, speculated that the posterior probability that is environment-friendly enterprises rose, and the probability that judged to be environmental pollution enterprises has declined.

According to (1), regulators' expected net social value is:

$$
\begin{aligned}
& E(\theta)_{\text {semi-separating equilibrium }}=\frac{p(g)}{p(g)+\phi p(b)} \times\left(\theta_{g}-t_{g} p_{h}\right)+ \\
& \frac{\phi p(b)}{p(g)+\phi p(b)} \times\left(\theta_{b}-t_{b} p_{h}\right)+(1-\phi)\left(\theta_{b}-t_{b} p_{l}\right) .
\end{aligned}
$$

When $\phi=0$, the semi-separating equilibrium will translate into a separating equilibrium, that is:

$$
\begin{aligned}
& E(\theta)_{\text {semi-separating equilibrium }}=\theta_{g}-t_{g} p_{h}+ \\
& \theta_{b}-t_{b} p_{l}=E(\theta)_{\text {separating equilibrium }}
\end{aligned} . \text { When } \phi=1 \text {, the }
$$

semi-separating equilibrium will translate into pooling equilibrium, that is:

$$
\begin{aligned}
& E(\theta)_{\text {semi-separating equilibrium }}=p(g)\left(\theta_{g}-t_{g} p_{h}\right)+p(b) \\
& \left(\theta_{b}-t_{b} p_{h}\right)=E(\theta)_{\text {pooling equilibrium }}
\end{aligned} .
$$

\section{AN EXAMPLE}

Assume enterprise profits without carbon emissions reduction is $R$, after the carbon emissions reduction enterprise profit is $R-C_{a}$. Carbon dioxide emissions depend upon the level of emissions reductions, emission reduction into the higher and lower carbon emissions. To make it simple, there are two levels: less carbon emission and more carbon emission levels. Less carbon emissions caused by damage to the environment is $D^{l}$, and it should be paid as a carbon tax: $T$; More carbon emission for environmental damage is $D^{h}$ $\left(D^{h}>D^{l}\right)$, subject to a carbon tax as $T+\Delta T(\Delta T>0)$. When the enterprise false reporting of carbon emissions (generally understating its carbon emissions), and the cost of government regulators to regulate enterprise carbon emissions is $C_{m}$, and probability of identification of the corporate emissions is $\alpha$. When found to be low-carbon emissions, enterprises not only need to pay a carbon tax $\Delta T$, but extra pay a fine as $F$.

It can be seen that between government regulators and enterprises formed the incomplete information static game, the game returns the matrix can be used to describe, which is shown in Table $\mathbf{1}$ and Table $\mathbf{2}$.

When government regulators do not monitor, regardless of which type of production enterprises belong to, the optimal strategy is more productive and more carbon emissions 
Table 1. Income matrix of regulators and the pollution enterprises.

\begin{tabular}{|c|c|c|c|}
\hline \multirow{2}{*}{} & \multicolumn{2}{|c|}{ Environmental Pollution Enterprise (b) } \\
\cline { 3 - 4 } & Less Emissions $(\boldsymbol{L})$ & More Emissions $(\boldsymbol{H})$ \\
\hline \hline \multirow{3}{*}{ government } & Regulation $(M)$ & $T-D^{l}-C_{m}, \quad R-T-C_{a}^{b}$ & $T-D^{h}-C_{m}+\alpha(1-\phi)(\Delta T+F), \quad R-T-\alpha(\Delta T+F)$ \\
\cline { 2 - 4 } & Non-regulation $(N)$ & $T-D^{l}, \quad R-T-C_{a}^{b}$ & $T-D^{h}, \quad R-T$ \\
\hline
\end{tabular}

Table 2. Income matrix of regulators and the environmental-friendly enterprises.

\begin{tabular}{|c|c|c|c|}
\hline \multirow{2}{*}{} & \multicolumn{2}{|c|}{ Environmental-friendly Enterprises $(\mathrm{g})$} \\
\cline { 3 - 4 } & & Less Emissions $(\boldsymbol{L})$ & More Emissions $(\boldsymbol{H})$ \\
\hline \hline \multirow{3}{*}{ government } & Regulation $(M)$ & $T-D^{l}-C_{m}, \quad R-T-C_{a}^{g}$ & $T-D^{h}-C_{m}+\alpha(1-\phi)(\Delta T+F), \quad R-T-\alpha(\Delta T+F)$ \\
\cline { 2 - 4 } & Non-regulation $(N)$ & $T-D^{l}, \quad R-T-C_{a}^{g}$ & $T-D^{h}, \quad R-T$ \\
\hline
\end{tabular}

Table 3. Optimal production measures for two categories of enterprises under the supervision of the regulator.

\begin{tabular}{|l|c|c|c|}
\hline \multicolumn{2}{|c|}{} & \multicolumn{2}{|c|}{ Environmental Pollution Enterprise (b) } \\
\cline { 3 - 4 } & & $C_{a}^{b}<\alpha(\Delta T+F)$ & $C_{a}^{b}<\alpha(\Delta T+F)$ \\
\hline \hline \multirow{3}{*}{ Environmental-friendly Enterprises $(g)$} & $C_{a}^{g}<\alpha(\Delta T+F)$ & $L, L$ & $H, L$ \\
\cline { 2 - 4 } & $C_{a}^{g}>\alpha(\Delta T+F)$ &,-- & $H, H$ \\
\hline
\end{tabular}

are observed. When government regulators monitor the production process, the optimal strategy of the enterprise depends on the cost of carbon emissions $C_{a}$, the probability of making a false report carbon emissions $\alpha$, the carbon taxes $\Delta T$, and the fines $F$. For businesses, saving carbon emissions abatement costs can be seen as a false report of earnings, need to pay carbon taxes and penalties can be regarded as false reporting of carbon emissions costs. When the overstatement of revenue is less than the cost of carbon emissions, that is $C_{a}<\alpha(\Delta T+F)$, and companies will choose to have fewer carbon emissions; Instead, companies will choose more carbon emissions. Under different conditions, the production strategy of enterprises is shown in Table 3.

At this point, discussions can be divided into three scenarios:

First, when the false reporting cost of carbon emissions is more than two types of emission reduction costs, that is, $\alpha(\Delta T+F)>C_{a}^{b}>C_{a}^{g}$, Enterprise optimal production strategy is less carbon emissions, and the Government expected profit is $E(\theta)=T-D^{l}-C_{m}$.

Second, when the false reporting cast of carbon emissions between two types of emission reduction cost, that is: $C_{a}^{b}>\alpha(\Delta T+F)>C_{a}^{g}$, the enterprise optimal production strategy is: the environmental pollution enterprise is to emit more carbon, and the environmental friendly enterprise is to emit less carbon. At this time, the expected value of government regulators is:

$$
E(\theta)=T-D^{h}-C_{m}+p(b) \alpha(1-\phi)(\Delta T+F)+p(g)\left(D^{h}-D^{l}\right) .
$$

For the regulation department of government, at this time, when

$p(b) \alpha(1-\phi)(\Delta T+F)+p(g)\left(D^{h}-D^{l}\right)>C_{m}$, the optimal strategy is to monitor; in contrast, is not to monitor.

Third, when false reporting cost of carbon emissions is less than two types of carbon emission costs, that is, $C_{a}^{b}>C_{a}^{g}>\alpha(\Delta T+F)$.

Optimal production policy of the enterprise is: two categories of enterprises are choosing more carbon emissions. At this point, the expected value of the Government sector is: $E(\theta)=T-D^{h}-C_{m}+\alpha(1-\phi)(\Delta T+F)$. When the Government regulatory emission costs is less than enterprise back carbon taxes and penalties, that is $C_{m}<\alpha(\Delta T+F)$.

The optimal choice is to monitor; in contrast, optimal strategy is not to regulate the production enterprises.

\section{CONCLUSION}

From the above analysis, it is shown that if there is asymmetric information about the cost of carbon emissions reduction between government departments and enterprises, 
the regulators to supervise carbon emissions cannot achieve its optimal control. In this case, carbon emissions will exceed the optimal emission level. Through the solution of the semi-separating equilibrium, balanced results that were obtained in order to reduce carbon dioxide emissions, needed a carbon tax, increased fine and reduced carbon emission reduction costs. At the same time, to reduce supervise costs, at this point, whether carbon-dependent businesses were environmental pollution or environmental-friendly enterprises both reduced carbon emissions.

From this conclusion, some interesting suggestions may be obtained. Firstly, improving the carbon tax, increasing the fine efforts, will increase the cost of corporate carbon emission hoax; Secondly, to establish a sound regulatory system, basic institutional conditions for government regulation and reliance on social forces together to supervise enterprises behavior, will increase the risk of overstatement of carbon emissions; Thirdly, scientific system should be supervised, controls must be optimized to reduce regulatory costs; lastly, creating favorable market conditions through improvement of carbon emissions trading system, reduce cost and carbon emission hoax gains may render the "low emission" as the optimal production policy.

\section{CONFLICT OF INTEREST}

The authors confirm that this article content has no conflicts of interest.

\section{ACKNOWLEDGEMENTS}

Nature Science Foundation of Zhejiang Province (No: LY12G03002); Social Science Foundation of Zhejiang Province(No:12JCGL16YB).

\section{REFERENCES}

[1] F. Bosello, and R. Roson, "Carbon emissions trading and equity in international agreements,"Environmental Monitoring and Assessment, no. 7, pp. 29-37, 2002.

[2] J. C. Steckel, M. Kalkuhl, and R. Marschinski, "Should carbonexporting countries strive for consumption-based accounting in a global cap-and-trade regime?" Climatic Change, published online, vol. 100 , no. $3,2010$.

[3] C. A. Grainger, and C. D. Kolstad, "Who pays a price on carbon?" Environmental and Resource Economics, published online, vol. 46, no.3, pp. 359-376, 2010.

[4] S. E. Puliafito, J.L. Puliafito, and M. C. Grand, "Modeling population dynamics and economic growth as competing species: an application to $\mathrm{CO}_{2}$ global emissions," Ecological Economics, vol. 65, no.3, pp. 602-615, 2008.

[5] M. Dalton, B. O’Neill, A. Prskawetz, L. Jiang, and J. Pitkin "Population aging and future carbon emissions in the United States," Energy Economics, vol.30, no.2, pp. 642-675, 2008.

[6] U. Soytas, R. Sari, and B. T. Ewing, "Energy consumption, income, and carbon emissions in the United States," Ecological Economics, vol.62, no.3-4, pp. 482-489, 2007.

[7] X. Yingzhi, and Z. Fang, "Carbon reduction responsibility of china's industries based on the input-output analysis," Industrial Economics Research, no.5, pp. 27-35, 2010

[8] W. Mingxi, W. Mingrong, W. Shouyang and S. Wei, "A theoretical analysis of optimal emission reduction decision and its implementation," Management Review, no.6, pp. 42-47, 2010.

[9] Wa. Feng, W. Lihua and Y.Chao, "Driving factors for growth of carbon dioxide emissions during economic development in China," Economic Research Journal, no.2, pp. 123-136, 2010.

[10] B. Shusong, and W. Dayi, "Empirical evidence of the relation among energy consumption, carbon dioxide emissions and economic growth based on the abatement costs," Research on Economics and Management, vol.101, no.6, pp. 5-11, 2010.

[11] W. Zhongying, and W. Limao, "Economic growth and its effects on carbon emission in China," Journal of Safety and Environment, no.10, pp. 88-91, 2006.

[12] Y. Rong, and Z. Xian, "Probing into the mechanism of carbon constraints to economic growth in China," Statistics and Decision, no.7, 2009 .

(C) Tang and Song; Licensee Bentham Open.

This is an open access article licensed under the terms of the Creative Commons Attribution Non-Commercial License (http://creativecommons.org/licenses/by-nc/3.0/) which permits unrestricted, non-commercial use, distribution and reproduction in any medium, provided the work is properly cited. 